\title{
Later health-related quality of life in adults who have sustained spinal cord injury in childhood
}

\author{
M Kannisto ${ }^{1}$ and $\mathrm{H}$ Sintonen ${ }^{2}$ \\ ${ }^{1}$ Children's Hospital, University of Helsinki; ${ }^{2}$ Department of Health Policy and Management, University of Kuopio, \\ Finland
}

The outcome in terms of health-related quality of life (HRQL) in pediatric spinal cord injury (SCI) was studied in 36 adults who had sustained an SCI in childhood. The patients were interviewed and clinically examined. HRQL was assessed with the $15 \mathrm{D}$, a generic fifteendimensional self-administered HRQL instrument.

The 15 multiple-level dimensions are moving, seeing, hearing, breathing, sleeping, eating, communicating, urinary continence, working, social participation, mental functioning, pain, depression, distress and perceived health. The respondents choose, for each dimension, the level that best describe their health status.

In the $15 \mathrm{D}$ valuation system the respondents first assign a relative importance weight to each dimension and then a relative value to the levels on each dimension. To derive the $15 \mathrm{D}$ HRQL score on a $0-1$ scale the level values and importance weights are multiplied and combined with the levels chosen.

The average HRQL score of this SCI group was significantly lower than that measured in the population sample. The average importance weights assigned by the SCI group differed significantly $(P<0.05)$ from those assigned by the general population on several dimensions. The weights assigned by the SCI group were higher for the dimensions of mental functioning, communicating, social participation and seeing and lower for moving, working, sleeping and eating. These differences in valuing the dimensions of HRQL can influence behaviour and should therefore be taken into consideration in rehabilitation.

Keywords: spinal cord injuries; health-related quality of life; pediatric spinal cord injury; functional assessment

\section{Introduction}

Measuring health-related quality of life (HRQL) is commonly seen as a necessary and useful approach to evaluating effectiveness and efficiency of health care interventions in clinical trials. The results can also be used for improving clinical practice and assessing clinical outcomes. HRQL can be defined as a multidimensional concept which encompasses the physical, emotional and social components associated with illness or treatment. ${ }^{1}$

The psychosocial outcome and psychological adjustment to SCI have been extensively studied during the last decade. ${ }^{2,9-13,18}$ These studies have yielded useful information about short- and long-term adjustment to SCI and coping with SCI. Research has often been focused on the adult population, but little is known about the final outcome of children with SCI. Almost all we know in this respect has been extracted and generalised from cross-sectional studies of children with severe injuries. These studies show

Correspondence: M Kannisto, Department of Physiatry, Peijas Hospital, Sairaalakatu 1, FIN01400 Vantaa, Finland that young people adjust better than those who are older. ${ }^{3}$

The purpose of this study was to investigate the outcome in terms of HRQL of children who had sustained an SCI and were adults at the time of examination.

\section{Patients and methods}

This study was part of a larger multifaceted outcome study of pediatric SCI. The patients were identified from the membership register of the Finnish Association of the Disabled, the patient databases of the Käpylä Rehabilitation Centre (Helsinki), the Hospital of Invalid Foundation (Helsinki) and the Children's Hospital (University of Helsinki). The catchment population of these institutions is approximately 5 million.

Of the 66 persons contacted for this study 47 agreed to paticipate and 46 returned the $15 \mathrm{D}$ HRQL questionnaire and another questionnaire mapping out the type of injury. The final group consisted of $36 \mathrm{SCI}$ patients who had sustained SCI under the age of 17 
years and participated in this detailed multidisciplinary clinical survey in a hospital.

The reasons for excluding 11 persons were (i) an insufficient severity of SCI or doubtful nature of the neurological lesion (eg. meningomyelocele which were excluded from the study) $(n=3)$, (ii) poor cooperation because of associated mental deficiency $(n=1)$, (iii) unwillingness to travel or to take part in examinations in hospital $(n=6)$, and (iv) patient died before examinations $(n=1)$.

Two of the excluded patients were women. The mean age of excluded patients at injury was 10.1 years (SD 6.2, range at birth to 16.5 years) and the mean age at entering the study was 41 years (SD 14.4, range from 18.2 to 60.5 years).

The final study group comprised 11 females $(30 \%)$ and 25 males. When entering the study the mean age was 31.3 years (SD 9.9, range 18.1-63.3 years). In terms of age, the 63 year-old was a clear outlier; the rest were under 50 years of age, as can also be inferred from the mean. The mean time elapsed since injury was 20 years (SD 11.2, range 3.4-56.7 years) and the mean age at injury was 11.3 years (SD 5.1, range birth -17.1 years).

\section{Clinical examination}

All patients were clinically examined and structurally interviewed with a list of questions dealing with details of anamnestic information about injury, its treatment, possible complications and the person's past and present psychosocial condition. The spinal lesions were classified according to the level of the injury and completeness of the injury according to the standards of neurological classification of spinal injured patients. ${ }^{4}$

The 15D questionnaire and valuation method

HRQL was measured by using the $15 \mathrm{D} .^{5}$ The $15 \mathrm{D}$ questionnaire consists of 15 multiple choice questions each representing one health-related dimension. The

Table 1 The descriptions for levels of the social participation dimension

1 ( ) I am able to participate normally (as usual) in social interaction and activities, eg clubs, meetings, visits, etc.

2 ( ) Because of my health, I have had to restrict slightly my usual participation in social interaction and activities.

3 ( ) Because of my health, I have had to restrict considerably my usual participation in social interaction and activities.

4 ( ) Because of my health, I have had to give up almost entirely my usual participation in social interaction and activities.

5 ( ) Because of my health, I have had to give up completely my participation in social interaction and activities. dimensions are moving, seeing, hearing, breathing, sleeping, eating, communicating, urinary continence, working, social participation, mental functioning, pain, depression, distress and perceived health. The person ticks, for each dimension, the level that best describes her or his health status. For example, the levels of the dimension of social participation are described in Table 1. In routine use, this questionnaire only requires completion by the subject.

The 15D score, representing the overall HRQL and ranging from 0 (being dead) to 1 (full $\mathrm{HRQL}$ ) is calculated by combining the dimension importance weights and within-dimension level desirability values, elicited from subjects through a two-stage valuation procedure based on multi-attribute utility theory, ${ }^{6,7}$ with the responses to the 15 questions as follows:

where $\mathrm{I}_{\mathrm{ij}}=\mathrm{a}$ positive constant for the $\mathrm{jth}$ dimension, representing the relative importance individual $i$ attaches to it $(\mathrm{j}=1,2, \ldots \mathrm{n})$, and $\mathrm{W}_{\mathrm{ij}}\left(\mathrm{x}_{\mathrm{j}}\right)=$ a numerical function on the jth dimension, representing the value individual i places on various levels of the dimension. ${ }^{5}$

To obtain the dimension importance weights the subjects indicate the relative position of each of the 15 dimensions on an adjacent ratio scale $(0-100)$ by placing the dimension considered most important at 100. The individual values given to a dimension by all the subjects are averaged and then transformed so that the sum of the 15 average importance weights equals 1 .

The within-dimension discrete levels are valued similarly using a $0-100$ ratio scale and placing the most desirable level at 100 . The individual values given to the levels are then averaged and divided by 100 .

By averaging the levels ticked by the respondents on each dimension one can derive the $15 \mathrm{D}$ profile for the respondents, ie., indicate the group's average position on the dimensions.

The valuations were elicited from the 36 participants. They also assessed their overall health status with a $0-100$ visual analogue scale (VAS). VAS has originally been used to measure pain but its responsiveneness, validity and good test-retest reliability in quality of life questionnaires has been established. ${ }^{8,9}$

\section{The controls}

The valuations and $15 \mathrm{D}$ scores supplied by a random sample of 372 Finnish men and women, aged between 16 and 46, were used as reference values for the study group. ${ }^{10}$ In this comparison group the average age is the same as in the study group.

\section{Statistical methods}

All data was stored on DBASE III plus (Ashton-Tate). A computer algorithm written on Excel 4.0 (Microsoft Corporation) was used to calculate the HRQL scores 
and the statistical analyses were carried out with the Statgraphics (Statistical Graphics Corp.).

The standard Pearson product moment correlation coefficient was used for analysing the relationship between the HRQL and VAS scores. The $t$-test was used to examine the differences between the groups.

\section{Results}

The study group consisted of $28(78 \%)$ complete and eight incomplete SCI-patients (Table 2). Of the injuries $30(83 \%)$ were traumatic in nature, five $(16 \%)$ patients had a medical and one an iatrogenic cause behind the SCI. About half $(47 \%)$ of the patients were living with their family, the rest were living alone. None of the patients was permanently hospitalised. The majority $(67 \%)$ of the subjects had a gainful occupation and 12 of the patients $(33 \%)$ lived on a disability pension. Half of the patients had either a primary school $(25 \%)$ or secondary school level education $(25 \%)$. Remarkably many $(50 \%)$ had a university degree or were studying at the university. Only three $(8 \%)$ of the subjects had no driver's licence and never drove.

\section{Average importance weights}

The average importance weights indicate how important each of the fifteen dimensions is to the respondents. Respondents who had sustained SCI in childhood assigned a significantly higher importance weight to the dimensions of mental functioning, communicating, social participation and seeing than the controls (Table 3). The latter in turn assigned a higher weight to the dimensions of moving $(P<0.0001)$, working $(P<0.0001)$, sleeping and eating (Table 3).

The $15 D$ score

The average $15 \mathrm{D}$ score in the SCI group was 0.906 , $\mathrm{SD}=0.058$ and range $0.726-0.996$. The $15 \mathrm{D}$ score in the control group was $0.929, \mathrm{SD}=0.083$. The difference in $15 \mathrm{D}$ score is statistically significant $(P<0.05)$. In the SCI group the most marked deviations from the best level of functioning occurred on the dimensions of continence, moving, working and pain.

Table 2 Classification of patients according to the level of the lesion

\begin{tabular}{lcc}
\hline & $\begin{array}{c}\text { Complete } \\
\text { ASIA A }\end{array}$ & $\begin{array}{c}\text { Incomplete } \\
\text { ASIA BCD }\end{array}$ \\
\hline Tetraplegic & & \\
$\quad$ High (C1-5) & 2 & 3 \\
$\quad$ Intermediate (C6) & 1 & 2 \\
Paraplegic & & \\
High (T1-T6) & 8 & 1 \\
Low (T7- ) & 17 & 2 \\
& 28 & 8 \\
\hline
\end{tabular}

The average within-dimension level of the respondents in the SCI group and population sample differed significantly on the dimensions of moving, eating, urinary continence, working, social participation, mental function, depression and distress. Apart from the last three dimensions the SCI group scored worse ( 1 being the best level) (Table 4 ).

The average overall health status reported on the VAS was 82.3, $\mathrm{SD}=15.5$ and range $35-100$. A significant correlation between the HRQL and VAS scores was found, $r=0.33 ; P=0.044$.

Table 3 The average importance weights of the dimensions in the SCI group and population sample

\begin{tabular}{lccc}
\hline Dimension & $\begin{array}{c}\text { SCI } \\
(n=36)\end{array}$ & $\begin{array}{c}\text { Population } \\
\text { sample } \\
(n=372)\end{array}$ & $\begin{array}{c}\text { Stat. } \\
\text { signif. }\end{array}$ \\
\hline Moving & 0.0557 & 0.0751 & $\mathrm{p}<0.0001$ \\
Seeing & 0.0770 & 0.0698 & $\mathrm{p}<0.05$ \\
Hearing & 0.0707 & 0.0647 & $\mathrm{~ns}$ \\
Breathing & 0.0857 & 0.0854 & $\mathrm{~ns}$ \\
Sleeping & 0.0639 & 0.0723 & $\mathrm{p}<0.05$ \\
Eating & 0.0665 & 0.0780 & $\mathrm{p}<0.05$ \\
Communicating & 0.0790 & 0.0723 & $\mathrm{p}<0.05$ \\
Continence & 0.0519 & 0.0573 & $\mathrm{~ns}$ \\
Working & 0.0477 & 0.0639 & $\mathrm{p}<0.0001$ \\
Social participation & 0.0713 & 0.0616 & $\mathrm{p}<0.05$ \\
Mental functioning & 0.0931 & 0.0846 & $\mathrm{p}<0.05$ \\
Pain & 0.0605 & 0.0557 & $\mathrm{~ns}$ \\
Depression & 0.0535 & 0.0480 & $\mathrm{~ns}$ \\
Distress & 0.0581 & 0.0567 & $\mathrm{~ns}$ \\
Perceived health & 0.0653 & 0.0646 & $\mathrm{~ns}$ \\
Sum & 1.0000 & 1.0000 & \\
\hline
\end{tabular}

Table 4 The average within-dimension level $(1-5,5$ is the worst) of the respondents on the dimensions in the SCI group and population sample

\begin{tabular}{lccc}
\hline Dimension & SCI & $\begin{array}{c}\text { Population } \\
\text { sample } \\
(n=372)\end{array}$ & $\begin{array}{c}\text { Stat. } \\
\text { signif. }\end{array}$ \\
\hline Moving & 2.222 & 1.073 & $\mathrm{p}<0.0001$ \\
Seeing & 1.056 & 1.065 & $\mathrm{~ns}$ \\
Hearing & 1.000 & 1.032 & $\mathrm{~ns}$ \\
Breathing & 1.139 & 1.158 & $\mathrm{~ns}$ \\
Sleeping & 1.444 & 1.464 & $\mathrm{~ns}$ \\
Eating & 1.194 & 1.034 & $\mathrm{p}<0.0001$ \\
Communicating & 1.000 & 1.058 & $\mathrm{~ns}$ \\
Continence & 2.944 & 1.106 & $\mathrm{p}<0.0001$ \\
Working & 2.083 & 1.187 & $\mathrm{p}<0.0001$ \\
Social participation & 1.361 & 1.140 & $\mathrm{p}<0.0001$ \\
Mental function & 1.083 & 1.185 & $\mathrm{p}<0.0001$ \\
Pain & 1.667 & 1.718 & $\mathrm{~ns}$ \\
Depression & 1.361 & 1.745 & $\mathrm{p}<0.0001$ \\
Distress & 1.222 & 1.468 & $\mathrm{p}<0.0001$ \\
Perceived health & 1.556 & 1.531 & $\mathrm{~ns}$ \\
\hline
\end{tabular}




\section{Discussion}

Many studies on HRQL as well as long-term followups of SCI patients have been published in recent years, ${ }^{11,12,14}$ however, as far as we know no reports focusing on the long-term follow-up of pediatric SCI patients have been published. In earlier studies on SCI patients HRQL has been found to be high and comparable to the population scores even though SCI patients exhibit a higher degree of physical disability. The scores of the adjusted patients with older injuries tend to approach the scores of the normal population or may be even higher. ${ }^{13,14}$ The findings of this study are similar to those of Mehnert. In a study of 675 subjects with various disabilities, he found that those whose disabling condition occurred before the age of twenty years expressed greater life satisfaction than those who were injured later in life. ${ }^{3}$ Longitudinal studies have also shown that adjustment continues and improves for years after the initial injury. ${ }^{15}$

The 15D HRQL score was $0.929(\mathrm{SD}=0.083)$ in a random sample of the normal population consisting of 372 persons aged between $16-46$ years. ${ }^{10}$ The HRQL score among the SCI patients under study was 0.906 $(\mathrm{SD}=0.058)$. This result is consistent with the findings of previous quality of life studies with SCI patients. ${ }^{13-15}$

It is to some extent questionable whether a generic HRQL measure like the $15 \mathrm{D}$ is able to cover all HRQL facets associated with a specific disease. Disease-specific instruments may be more sensitive to changes in HRQL, but at the cost of comparability across diseases. The $15 \mathrm{D}$ revealed that in the SCI group the most marked deviations from the best level of functioning occurred on the dimensions of urinary continence, moving, working and pain. The lack of dimensions measuring sexual activity and bowel function, in which many SCI patients encounter problems, partly reduces the sensitivity of the $15 \mathrm{D}$ among SCI patients. ${ }^{16-18}$ However, a new version of the $15 \mathrm{D}$ launched recently covers also those areas. ${ }^{19}$

The high level and completeness of SCI together with old age are known to predict poor long-time survival. $^{20}$ The relatively small number of complete tetraplegics and incomplete para- and tetraplegics in this study did not allow an analysis of the influence of injury level and completeness on HRQL. The results of studies on the impact of impairment or disability on HRQL or life satisfaction have been somewhat conflicting. ${ }^{21,22}$ The well-known impairments such as neurogenic urinary incontinence and physical problems with moving associated with SCI explain why the HRQL score of this patient group deviates from the score of the normal population.

Disability to work and urinary incontinence were the biggest problems and these dimensions also obtained the lowest average importance weights, in addition to the dimension of moving (Table 3). This finding corroborates that of Whiteneck et al who argued that the needs which are not well met are also ranked lower in importance. ${ }^{12}$ Is this due to a shifting in priorities among long-term SCI survivors or is it a question of an expression of denial and devaluation of needs which are not met? In our recent study on ego-defences in the same group of pediatric SCI patients the results are in favour of a somewhat modified ego-defence pattern leading to good adaptation. ${ }^{23}$ In this context the high HRQL score can be understood as an expression of good adjustment to a devastating injury, but with some specific changes in defensive personality functions.

The average within-dimension level of mental functioning, depression and distress was better in the SCI group than in the control group (Table 4). This strengthens the belief that even a severe handicap per se does not inevitably lead to problems in mental health. Our results indicate that the SCI patients who have sustained their injury in childhood have problems primarily on the dimensions of moving, working, urinary continence, eating and social participation. These dimensions are directly influenced by the physical impairment.

\section{Conclusions}

This study showed that HRQL scores among SCI patients who had sustained their injury in childhood are somewhat lower than those of the general population. The SCI patients assigned a lower average importance weight to the dimensions of moving and working than the normal reference population. Despite low importance ascribed to working this patient group turned out to be remarkably often gainfully employed or highly educated. This SCI patient group performed well on the dimensions of communicating, hearing, seeing, breathing, mental function, depression and distress, but faced the biggest problems with continence, moving, social participation and working. Therefore, to further improve the HRQL of these patients with rehabilitation, more emphasis should be placed on these dimensions to compensate for the physical consequences of the pediatric SCI.

Similar HRQL studies are recommended also in other patient groups when health care interventions are planned for improving HRQL.

\section{References}

1 Revicki D. Health related quality of life in the evaluation of medical therapy for chronic illness. The Journal of Family Practice 1989; 29: 377.

2 Richards S. Psychologic adjustment to spinal cord injury during first postdischarge year. Arch Phys Med Rehabil 1986; 67: $362-$ 365.

3 Mehnert T. Correlates of life satisfaction in those with disabling conditions. Rehabilitation Psychology 1990; 35: 3- 17.

4 ASIA/IMSOP (1992). International Standards for Neurological and Functional Classification of Spinal Cord Injury-Revised 1992. American Spinal Cord Injury Association, Chicago.

5 Sintonen H, Pekurinen M. A fifteen-dimensional measure of health-related quality of life (15D) and its applications. In: Walker S, Rosser R (eds). Quality of Life Assessment: Key Issues in the 1990s. Kluwer Academic Publishers: Dordrecht 1993; pp. $185-195$. 
6 Sintonen H. An approach to economic evaluation of actions for health. A theoretical-methodological study in health economics with special reference to Finnish health policy. Official Statistics of Finland. Special Social Studies XXXII: 74, Government Printing Centre: Helsinki 1981, pp 185-206.

7 Sintonen $\mathrm{H}$. An approach to measuring and valuing health states. Soc Sci Med 1981; 15C: 55-65.

8 Gudex C, Dolan P, Kind P, Williams A. Health state valuations from general public using the visual analogue scale. Qual Life Res 1996; 5: $521-531$.

9 Jaeschke R, Singer J, Guyatt H. Comparison of seven-point and visual analogue scales. Data from a randomized trial. Contro Clin Trials 1990; 11: 43-51.

10 Rissanen P, Sintonen H, Pekurinen M. The 15D scores in the adult normal population in Finland. Unpublished data.

11 Stensman R. Adjustment to traumatic spinal cord injury. A longitudinal study of self-reported quality of life. Paraplegia 1994; 32: $416-422$

12 Whiteneck G et al. Mortality, morbidity, and psychosocial outcomes of persons spinal cord injured more than 20 years ago. Paraplegia 1992; 30: 617-630.

13 Lundqvist $\mathrm{C}$ et al. Spinal cord injuries, clinical, functional, and emotional status. Spine 1991; 1: $78-83$

14 Eisenberg M, Saltz C. Quality of life among aging spinal cord injured persons. Long term rehabilitation outcomes. Paraplegia 1991; 29: $514-520$.

15 Krause J. Longitudinal changes in adjustment after spinal cord injury: A 15-year study. Arch Phys Med Rehabil 1992; 73: $564-$ 568.
16 White $\mathrm{M}$ et al. Sexual activities, concerns and interests of men with spinal cord injury. Am J Phys Med Rehabil 1992; 4: $225-$ 231.

17 Longo W, Ballantyne G, Modlin I. The colon, anorectum and spinal cord patient. A review of the functional alterations of the denervated hindgut. Dis col rectum 1989; 32: $261-267$.

18 Kannisto M, Rintala R. Bowel function in adults who have sustained spinal cord injury in childhood. Paraplegia 1995; 33: $701-703$

19 Sintonen H. The 15-D measure of health-related quality of life: reliability, validity and sensitivity of its health state descriptive system. Working paper 41. National centre for health program evaluation 1994. Melbourne, Australia.

20 DeVivo M, Stover S, Black K. Prognostic factors for 12-year survival after spinal cord injury. Arch Phys Med Rehabil 1992; 73: $156-162$.

21 Clayton K, Chubob R. Factors associated with the quality of life of long-term spinal cord injured persons. Arch Phys Med Rehab 1994; 75: $633-638$

22 Fuhrer $\mathrm{M}$ et al. Relationship of life satisfaction to impairment, disability, and handicap among persons with spinal cord injury living in the community. Arch Phys Med Rehabil 1992; 73: $552-$ 557.

23 Sammallahti P, Kannisto M, Aalberg V. Psychological defenses and psychiatric symptoms in adults with pediatric spinal cord injury. Spinal Cord 1996; 34: 669-672. 